\title{
Unique clinicopathological features of metaplastic breast carcinoma compared with invasive ductal carcinoma and poor prognostic indicators
}

\author{
Yanni Song ${ }^{1}$, Xiaolong Liü ${ }^{2,3}$, Guoqiang Zhang ${ }^{1}$, Hongtao Song ${ }^{2}$, Yanlv Ren ${ }^{1}$, Xiaoguang He ${ }^{1,4}$, Yanbo Wang ${ }^{1}$, \\ Jinfeng Zhang ${ }^{1}$, Youxue Zhang ${ }^{1}$, Shanshan Sun ${ }^{1}$, Xiaoshuan Liang ${ }^{1}$, Qian Sun ${ }^{1}$ and Da Pang ${ }^{1,5^{*}}$
}

\begin{abstract}
Background: Metaplastic breast carcinoma is a rare aggressive malignant neoplasm. The purposes of this study are to review the pathologic features and clinical outcomes of metaplastic breast carcinoma compared to invasive ductal carcinoma and to evaluate the prognosis of metaplastic breast carcinoma.

Methods: The cases of 55 patients with metaplastic breast carcinomapresenting between 1991 and 2006 were analyzed and compared to the cases of 767 age-matched patients with invasive ductal carcinoma from the same time period.

Results: The group of patients with metaplastic breast carcinoma presented with a larger tumor size, lower lymph node involvement, higher percentage of triple-negative (estrogen receptor-, progesterone receptor- and human epidermal growth factor receptor-2-negative) cases, and Ki-67 over-expression compared with the group of patients with invasive ductal carcinoma and triple-negative invasive ductal carcinomas. Patients in the metaplastic breast carcinoma group tended to have more local (often chest wall) recurrences $(P=0.038)$ and distant (often lung) metastases $(P=0.001)$ than those in the invasive ductal carcinomas group. The prognosis of metaplastic breast carcinoma was poorer than that of invasive ductal carcinoma and triple-negative invasive ductal carcinomas; the 5 -year overall survival rate was $54.5 \%$ in metaplastic breast carcinoma versus $85.1 \%$ in invasive ductal carcinoma, and $73.3 \%$ in triple-negative invasive ductal carcinomas $(P<0.001)$. The 5 -year disease-free survival rate was $45.5 \%$ in metaplastic breast carcinoma versus $71.2 \%$ in invasive ductal carcinoma, and $60.3 \%$ in triple-negative invasive ductal carcinomas $(P<0.001)$. Multivariate analysis revealed tumor size larger than $5.0 \mathrm{~cm}$, lymph node involvement and Ki-67 $\geq 14 \%$ were significantly related to 5 -year overall survival $(P=0.010 ; P=0.010 ; P=0.035)$ and 5 -year disease-free survival $(P=0.020 ; P=0.018 ; P=0.049)$.
\end{abstract}

Conclusions: Metaplastic breast carcinoma shows a poorer prognosis than both invasive ductal carcinoma and triplenegative invasive ductal carcinomas. Tumor size larger than $5.0 \mathrm{~cm}$, lymph node involvement and Ki-67 $\geq 14 \%$ indicate a poor prognosis in patients with metaplastic breast carcinoma.

Keywords: Breast cancer, Clinical outcomes, Metaplasia, Pathologic features, Prognosis

\section{Background}

Metaplastic breast carcinoma $(\mathrm{MBC})$ is a rare malignancy characterized by various combinations of adenocarcinoma with mesenchymal and epithelial components. It exhibits a variety of histopathologic patterns and appears to be both epithelial and mesenchymal in origin. MBC accounts for

\footnotetext{
* Correspondence: pangdasir@163.com

'Department of Breast Surgery, The Third Affiliated Hospital of Harbin

Medical University, 150 Haping Road, Harbin 150081, China

${ }^{5}$ Heilongjiang Institute for Cancer Research, 6 Baojian Road, Harbin 150040,

China

Full list of author information is available at the end of the article
}

less than $1 \%$ of all breast carcinomas [1]. Because it was not officially recognized as a distinct histopathologic subtype until 2000, knowledge about patient demographics, presentation, tumor characteristics, prognosis and treatment patterns is limited. The World Health Organization have classified MBC into pure epithelial-type and mixed epithelial and mesenchymal type [2]. The epithelial-type $\mathrm{MBC}$ is subclassified into squamous cell carcinoma (SCC), adenosquamous carcinoma (ASC) and adenocarcinoma with spindle cell differentiation (SPC); mixed type $\mathrm{MBC}$ is subclassified into carcinosarcoma
C Biomed Central

(c) 2013 Song et al.; licensee BioMed Central Ltd. This is an Open Access article distributed under the terms of the Creative Commons Attribution License (http://creativecommons.org/licenses/by/2.0), which permits unrestricted use, distribution, and reproduction in any medium, provided the original work is properly cited. 
(CS) and carcinoma with osseous and chondroid metaplasia (COC).

MBC differs from typical invasive ductal carcinoma (IDC) in several pathological and clinical aspects, and the prognosis and optimal treatment for $\mathrm{MBC}$ are largely not well studied. To date, only small series and case reports have attempted to delineate the factors that make $\mathrm{MBC}$ different from more common malignant breast cancer [3-5]. Recently, much attention has been paid to $\mathrm{MBC}$ because this neoplasm is usually characterized by a lack of estrogen receptor (ER), progesterone receptor (PR) and human epidermal growth factor receptor-2 (HER2) over-expression, which is called triple negativity [6]. Triple-negative breast cancer has been known to be resistant to conventional endocrine therapy for hormone receptor-positive breast cancer or targeted therapies such as trastuzumab for HER2 over-expressing breast cancer [7-9]. It has been reported that the risk of tumor recurrence of $\mathrm{MBC}$ is higher than in typical breast cancer. However, this remains controversial [10-12]. The purpose of this study is to clarify these controversies. To this end, we compared the clinicopathological characteristics, management and prognosis of 55 patients with $\mathrm{MBC}$ with those of 767 patients with IDC, including 131 triple-negative IDC (TN-IDC) patients, treated at the Third Affiliated Hospital of Harbin Medical University (3rd AHHMU) from 1991 to 2006.

We analyzed indicators that affect the prognosis of patients with $\mathrm{MBC}$ and that could potentially be used to optimize systemic treatment to prevent relapse in the future.

\section{Methods}

Patients' characteristics

Patients were selected from the database of the Breast Cancer Center at the 3rd AHHMU between 1991 and 2006 (7,523 patients) (Figure 1). Only patients who had surgical pathological specimens of the primary tumor available for review were included. Fifty-five patients had been diagnosed with $\mathrm{MBC}$ and were included in this analysis; there were no patients with distant metastasis at the time of diagnosis. These available cases were compared with 767 IDC cases matched for age and period of diagnosis. The patients' medical records were retrospectively reviewed to obtain demographic, clinicopathologic, treatment and prognostic information as well as the immunohistochemistry of biologic factors such as ER, PR, HER2, P53 and Ki-67. Patients with IDC who presented with a recurrent tumor, metastatic disease at presentation, male tumor, bilateral tumors, previous tumors in other sites, or those who had previously received neoadjuvant treatment were excluded. No patient received any therapy before surgery. All patients were followed until death or the study closing date (30 December 2011).

\section{Histopathology}

At initial diagnosis, all tumor specimens were reviewed by two pathologists at the 3rd AHHMU. Tumor specimens were histologically examined, and cases were included in the re-review (55 $\mathrm{MBC}$ cases) if adenocarcinomatous elements were identified as admixed with SCC, spindle cell, chondroid or osseus tumor basing on hematoxylin and eosin staining and/or immunohistochemistry (IHC). Four-micron tissue sections, prepared from a formalin-fixed paraffin-embedded representative of the tumor samples, were used. The histological grade was determined according to the modified Bloom-Richardson classification. IHC staining for ER and PR (Zhongshan-Bio Co., Beijing, China) was performed using a conventional detection method and ER and PR status was evaluated based on the percentage of positively stained nuclei [13]. Positive staining for HER2 (Zhongshan-Bio Co.) was defined based on the percentage of tumor cells and the intensity of membrane staining. HER2 was scored as 0 to $3+$ according to the method recommended for the DakoHercepTest. Tumors with scores of 3 or with a $>2.2$ fold increase in HER2 gene amplification as determined by fluorescence in situ hybridization were considered to be positive for HER2 over-expression [14]. Cells stained for Ki-67 and P53 were counted and expressed as a percentage. Low expression was considered as Ki-67<14\% [15] and $\mathrm{P} 53<25 \%$ [5]. All protocols were reviewed and approved by the Ethical Committee of Harbin Medical University in Harbin, China. Informed consent was obtained from all the patients.

For subgroup analysis, the definition of triple-negative breast cancer was as follows: negative ER and PR by IHC, and negative HER2 represented by an IHC score of 0 or $1+$, or $2+$ if not amplified by fluorescence in situ hybridization. The cases with an IHC score of $2+$ for HER2 and no fluorescence in situ hybridization results were excluded from the triple-negative breast cancer group. In total, 131 of the control cases were classified as TN-IDC.

\section{Statistical methods}

Overall survival (OS) was calculated from the date of surgery until death or the date patients were last known to be alive. The disease-free survival (DFS) was calculated from the date of surgery until relapse or the date patients were last known to be alive. The primary end points of this study were 5-year OS and 5-year DFS. In order to compare the clinicopathological characteristics between the two groups, we used the Student t-test and $\chi^{2}$ test. The 5-year OS and 5-year DFS rates were calculated using the Kaplan-Meier method and comparisons were made between $\mathrm{MBC}$ and control patients using the log-rank test. For multivariate analysis, Cox regression analysis was used. Statistical analyses were performed using SPSS 17.0 


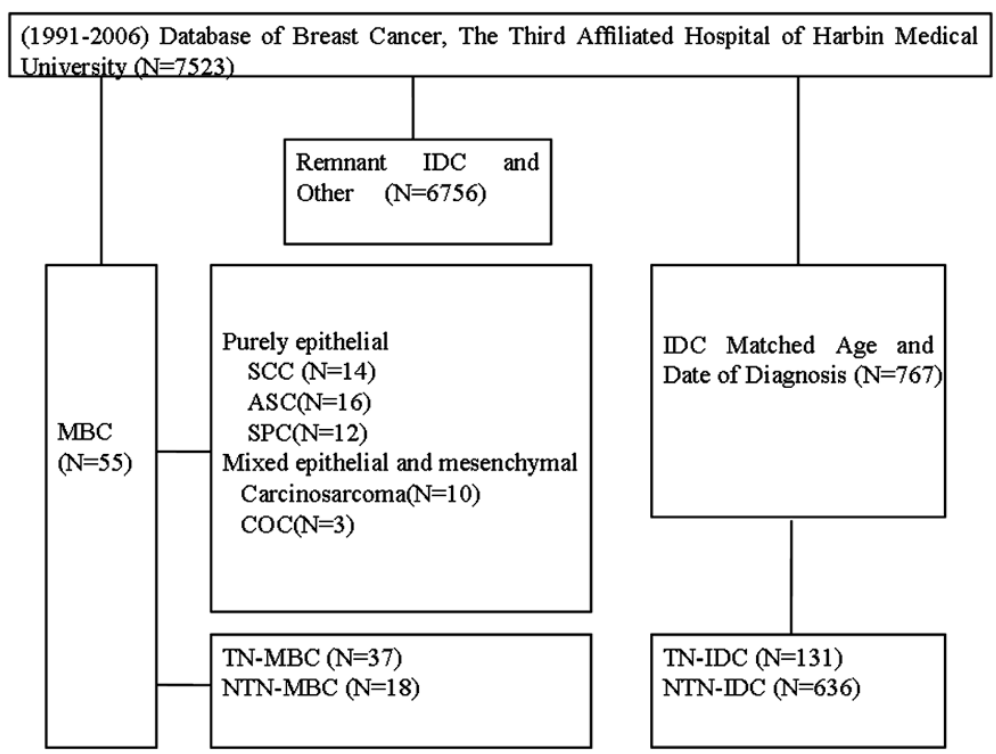

Figure 1 Patient overview. Patients treated between 1991 and 2006 were selected from the database of the Breast Cancer. ASC, adenosquamous carcinoma; COC, carcinoma with osseous and chondroid metaplasia; CS, carcinosarcoma; IDC, invasive ductal carcinoma; MBC, metaplastic breast carcinoma;NTN, not triple-negative; SCC, squamous cell carcinoma; SPC, adenocarcinoma with spindle cell differentiation; TN, triple-negative.

for Windows (Austin, TX, USA). A value of $P<0.05$ was considered statistically significant.

\section{Results}

\section{Clinicopathological features}

We retrieved $55 \mathrm{MBC}$ cases from the 3rd AHHMU database, representing $0.73 \%$ of the 7,523 breast cancer cases. All patients were female, with a median age of 50 years (range, 24 to 71 years). The median tumor size was $5.0 \mathrm{~cm}$ (range, 1.5 to $20.0 \mathrm{~cm}$ ). ASC was the most common histological subtype of $\mathrm{MBC}(\mathrm{N}=16)$, followed by SCC $(\mathrm{N}=14)$, SPC $(\mathrm{N}=12), \mathrm{CS}(\mathrm{N}=10)$ and COC $(\mathrm{N}=3)$. Clinicopathological features and treatment were analyzed for 55 patients with $\mathrm{MBC}$ and 767 patients with IDC (Table 1).

The MBC group presented with a significantly larger tumor size than the IDC group (>T2, 80\% versus 48\%, $P<0.001$ ) and with less nodal metastasis (negative nodal status, $64 \%$ versus $41 \%, P=0.001$ ). More patients in the MBC group had stage III disease at diagnosis $(29 \%$ versus $11 \%, P=0.001)$. The $\mathrm{MBC}$ group had significantly more cases with no hormone receptors or HER2 overexpression/gene amplification compared with the IDC group (ER-, $85 \%$ versus $45 \%, P<0.001$; PR-, $82 \%$ versus $36 \%, P<0.001$; HER2-, $84 \%$ versus $65 \%, P=0.005)$. There were significantly more triple-negative cases in the $\mathrm{MBC}$ group compared with the IDC group (67\% versus $17 \%$, $P<0.001)$. Fewer patients received adjuvant hormonal therapy in the MBC group than in the IDC group (24\% versus $68 \%, P<0.001)$. Over-expression of $\mathrm{Ki}-67$ was more common in the MBC group compared with the IDC group (Ki-67 $\geq 14 \%$, 87\% versus $63 \%, P=0.001$ ).

The patients in the $\mathrm{MBC}$ group received more radiotherapy and less hormonal therapy than those in the IDC group (radiotherapy, $49 \%$ versus $23 \%, P<0.001$; hormonal therapy, $24 \%$ versus $68 \%, P<0.001)$. There was no difference in the rates of chemotherapy and surgery between the two groups. Sentinel lymph node (SLN) biopsy in MBC was successful in eight of nine (89\%) patients. Negative SLNs (without metastasis in SLNs) were found in seven of eight (87\%) patients. In seven patients with negative SLNs, no positive non-SLN was found. SLN was not compared with IDC and TN-IDC due to small patient numbers.

Table 2 gives the different locations of the recurrent sites of MBC and IDC. Patients with local recurrence in the $\mathrm{MBC}$ group presented more chest wall recurrence than those in the IDC group $(P=0.038)$. Distant metastases were significantly more likely to be in the lung in patients with $\mathrm{MBC}$ but in the bone in patients with IDC $(P=0.001)$.

\section{Univariate analysis of the 5-year overall survival and 5-year disease-free survival}

Figure 2A, B presents the 5-year OS and 5-year DFS curves for MBC, IDC and TN-IDC. The prognosis was poorer for $\mathrm{MBC}$ than for IDC and TN-IDC, with a 5-year OS rate of $54.5 \%$ in $\mathrm{MBC}$ versus $85.1 \%$ in IDC and $73.3 \%$ in TN-IDC $(P<0.001)$. The 5 -year DFS rate was $45.5 \%$ in $\mathrm{MBC}$ versus 71.2\% in IDC and 60.3\% in TN-IDC $(P<0.001)$. 
Table 1 Clinicopathological features of metaplastic breast carcinoma, invasive ductal carcinoma and triple-negative invasive ductal carcinoma

\begin{tabular}{|c|c|c|c|c|c|}
\hline \multirow[b]{2}{*}{ Features } & \multirow{2}{*}{$\begin{array}{l}\text { Metaplastic breast cancer }(\mathrm{N}=55) \\
\mathrm{N}(\%)\end{array}$} & \multicolumn{2}{|c|}{ Invasive ductal carcinoma ( $\mathrm{N}=767$ ) } & \multicolumn{2}{|c|}{ TN-IDC (N = 131) } \\
\hline & & $\mathrm{N}(\%)$ & $P$ & $\mathrm{~N}(\%)$ & $P$ \\
\hline Age & & & 0.594 & & 0.264 \\
\hline$\leq 50$ & $27(49.09)$ & $405(52.80)$ & & $76(58.02)$ & \\
\hline$>50$ & $28(50.91)$ & $362(47.20)$ & & $55(41.98)$ & \\
\hline Stage & & & 0.001 & & $<0.001$ \\
\hline I & $4(7.27)$ & $107(13.95)$ & & $21(16.03)$ & \\
\hline$\|$ & $30(54.55)$ & $522(68.06)$ & & $92(70.23)$ & \\
\hline III & $16(29.09)$ & $87(11.34)$ & & $8(6.11)$ & \\
\hline Unknown & $5(9.09)$ & $51(6.65)$ & & $10(7.63)$ & \\
\hline Operation & & & 0.051 & & 0.054 \\
\hline Breast-conserving surgery & $4(7.27)$ & $134(17.47)$ & & $25(19.08)$ & \\
\hline Modified radical mastectomy & $51(92.73)$ & $633(82.53)$ & & $106(80.92)$ & \\
\hline Chemotherapy & & & 0.302 & & 0.295 \\
\hline Yes & $48(87.28)$ & $627(81.74)$ & & $106(80.91)$ & \\
\hline No & $7(12.73)$ & $140(18.25)$ & & $25(19.08)$ & \\
\hline Radiotherapy & & & $<0.001$ & & $<0.001$ \\
\hline Yes & $27(49.09)$ & $177(23.08)$ & & $29(22.14)$ & \\
\hline No & $28(50.91)$ & $590(76.92)$ & & $102(77.86)$ & \\
\hline Hormone therapy & & & $<0.001$ & & \\
\hline Yes & $13(23.64)$ & $522(68.06)$ & & - & \\
\hline No & $42(76.46)$ & $245(31.94)$ & & - & \\
\hline Pathological tumor stage & & & $<0.001$ & & $<0.001$ \\
\hline $\mathrm{T} 1(\leq 2 \mathrm{~cm})$ & $5(9.09)$ & $317(41.33)$ & & $58(44.27)$ & \\
\hline $\mathrm{T} 2(2-5 \mathrm{~cm})$ & $22(40.00)$ & $332(43.29)$ & & $55(41.98)$ & \\
\hline $\mathrm{T} 3(>5 \mathrm{~cm})$ & $22(40.00)$ & $39(5.08)$ & & $5(3.82)$ & \\
\hline Tx & $6(10.91)$ & $79(10.30)$ & & $13(9.92)$ & \\
\hline Pathological nodal stage & & & 0.001 & & 0.001 \\
\hline No & $35(63.64)$ & $314(41.20)$ & & $50(38.17)$ & \\
\hline N1-3 & $15(27.27)$ & 385 (49.93) & & $69(52.67)$ & \\
\hline $\mathrm{Nx}$ & $5(9.09)$ & $68(8.87)$ & & $12(9.16)$ & \\
\hline Histological grade & & & 0.167 & & 0.285 \\
\hline | or || & $29(52.73)$ & $461(60.10)$ & & 77 (58.78) & \\
\hline III & $20(36.36)$ & $227(29.60)$ & & $41(31.30)$ & \\
\hline Unknown & $6(10.91)$ & $79(10.30)$ & & $13(9.92)$ & \\
\hline $\mathrm{Ki}-67^{\mathrm{a}}$ & & & $<0.001$ & & $<0.001$ \\
\hline$\geq 14 \%$ & $47(87.27)$ & $486(63.36)$ & & $80(61.07)$ & \\
\hline$<14 \%$ & $8(12.73)$ & $281(36.64)$ & & $51(38.93)$ & \\
\hline $\mathrm{P} 53^{\mathrm{b}}$ & & & 0.001 & & 0.008 \\
\hline$\geq 25 \%$ & $28(50.91)$ & $221(28.81)$ & & $40(30.53)$ & \\
\hline$<25 \%$ & $27(49.09)$ & $546(71.19)$ & & $91(69.47)$ & \\
\hline Estrogen receptor & & & $<0.001$ & & \\
\hline+ & $8(14.55)$ & 419 (54.63) & & - & \\
\hline- & $47(85.45)$ & $348(45.37)$ & & - & \\
\hline
\end{tabular}


Table 1 Clinicopathological features of metaplastic breast carcinoma, invasive ductal carcinoma and triple-negative invasive ductal carcinoma (Continued)

\begin{tabular}{llll}
\hline $\begin{array}{l}\text { Progesterone receptor } \\
+\end{array}$ & $10(18.18)$ & $492(64.14)$ & $<0.001$ \\
- & $45(81.82)$ & $276(35.98)$ & - \\
Human epidermal growth factor receptor-2 & & & - \\
+ & $9(16.36)$ & $268(34.94)$ & - \\
- & $46(83.64)$ & $499(65.06)$ & - \\
TN-MBC & $37(67.27)$ & $131(18.22)$ & $<0.001$ \\
Not TN-MBC & $18(32.73)$ & $636(81.78)$ & - \\
\hline
\end{tabular}

${ }^{a}$ Median value for Ki-67 $=13.96,{ }^{b}$ Median value for P53 $=24.85$. TN-MBC, triple-negative metaplastic breast carcinoma; TN-IDC, triple-negative invasive ductal carcinoma.

Figure 2C, D presents the 5-year OS and 5-year DFS curves for TN-IDC and MBC subtypes. The prognosis of TN-IDC was better than any subtype of $\mathrm{MBC}$, with a 5 -year OS rate of $73.3 \%$ in TN-IDC versus $50.0 \%$ in SCC, $56.3 \%$ in ASC, $40.0 \%$ in SPC and $75.0 \%$ in CS $(P=0.039)$. With regards the 5 -year OS, SPC had the worst prognosis of the MBC subtypesand CS had the best. Looking at the 5-year DFS, patients with SCC showed more recurrence (35.7\%) than those with TN-IDC (59.5\%), ASC (50.0\%), SPC (41.7\%) and CS (50.0\%), although $P$ values of 5 -year DFS $(P=0.254)$ were not significant.

Multivariate analysis of the 5-year overall survival and 5-year disease-free survival in metaplastic breast cancer Multivariate analysis (Table 3) revealed that 5-year OS and 5-year DFS were significantly related to tumor size larger than $5.0 \mathrm{~cm}$ (5-year OS: hazard ratio (HR) 3.22, 95\% CI 1.32 to $7.89, P=0.010$; 5-year DFS: HR 2.96, 95\% CI 1.19 to $7.39, P=0.020$ ) and lymph node involvement (5-year OS: HR 3.17, 95\% CI 1.31 to 7.67, $P=0.010$; 5-year DFS: HR $1.59,95 \%$ CI 1.08 to 2.35, $P=0.018)$. Furthermore, both 5 -year OS and

Table 2 The different locations of the recurrent sites of metaplastic breast carcinoma and invasive ductal carcinoma

\begin{tabular}{llll}
\hline Recurrent sites & MBC $(\mathbf{N}=\mathbf{3 3})$ & IDC (N = 222) & $\boldsymbol{P}$ \\
\hline Local recurrence & 10 & 27 & 0.038 \\
$\quad$ Chest wall & $10(100 \%)$ & $18(67 \%)$ & \\
Axillary fossa & 0 & $9(33 \%)$ & \\
Distant metastasis & 23 & 193 & 0.001 \\
Lung and pleura & $14(61 \%)$ & $50(26 \%)$ & \\
Liver & $4(17 \%)$ & $15(8 \%)$ & \\
Bone & $4(17 \%)$ & $116(60 \%)$ & \\
Brain and meninges & $1(4 \%)$ & $12(6 \%)$ & \\
Others & 0 & 2 & \\
\hline
\end{tabular}

5-year DFS were significantly related to Ki-67 $\geq 14 \%$ (5-year OS: HR 2.93, 95\% CI 1.08 to $7.96, P=0.035$; 5-year DFS: HR 2.72, 95\% CI 1.00 to $7.41, P=0.049)$.

\section{Systemic therapy}

Of the 55 patients with $\mathrm{MBC}, 48$ received adjuvant chemotherapy. Table 4 details the adjuvant chemotherapy regimens administered to these patients along with the treatment outcomes. In 15 of these 48 patients, radiation therapy was administered subsequent to chemotherapy; in two of these patients, further disease progression occurred, with isolated recurrences to the chest wall (four months after primary therapy) and liver (six months after primary therapy). At last follow-up of the 55 patients with MBC, 33 had experienced disease relapse, including 10 patients with locoregional recurrence, and 23 had experienced distant metastasis. Of these 23 patients, 14 (60.9\%) had metastases to the lungs. The 23 patients were treated with various chemotherapy regimens for metastatic disease, including anthracyclines, carboplatin, taxanes, capecitabine, vinorelbine and trastuzumab. Only five patients $(21.7 \%)$ had a partial response to therapy, and five patients $(21.7 \%)$ had disease stabilization.

\section{Radiotherapy}

Of the 55 patients with MBC, 27were treated with adjuvant radiation therapy. Five of these 27 patients had a locoregional recurrence. The 5-year OS rate of the 28 patients without adjuvant radiation therapy was $40 \%$ and the 5-year DFS rate was $60 \%$, which were not different from those of the patients treated with radiation therapy. Fifteen patients received radiation therapy for recurrent disease,and four patients had more than one site irradiated. All patients experienced a partial response or symptomatic improvement but, in five patients, disease progression occurred within the irradiated site (two locoregional, one lung, one meningeal and bone) in an average of 4 months. 

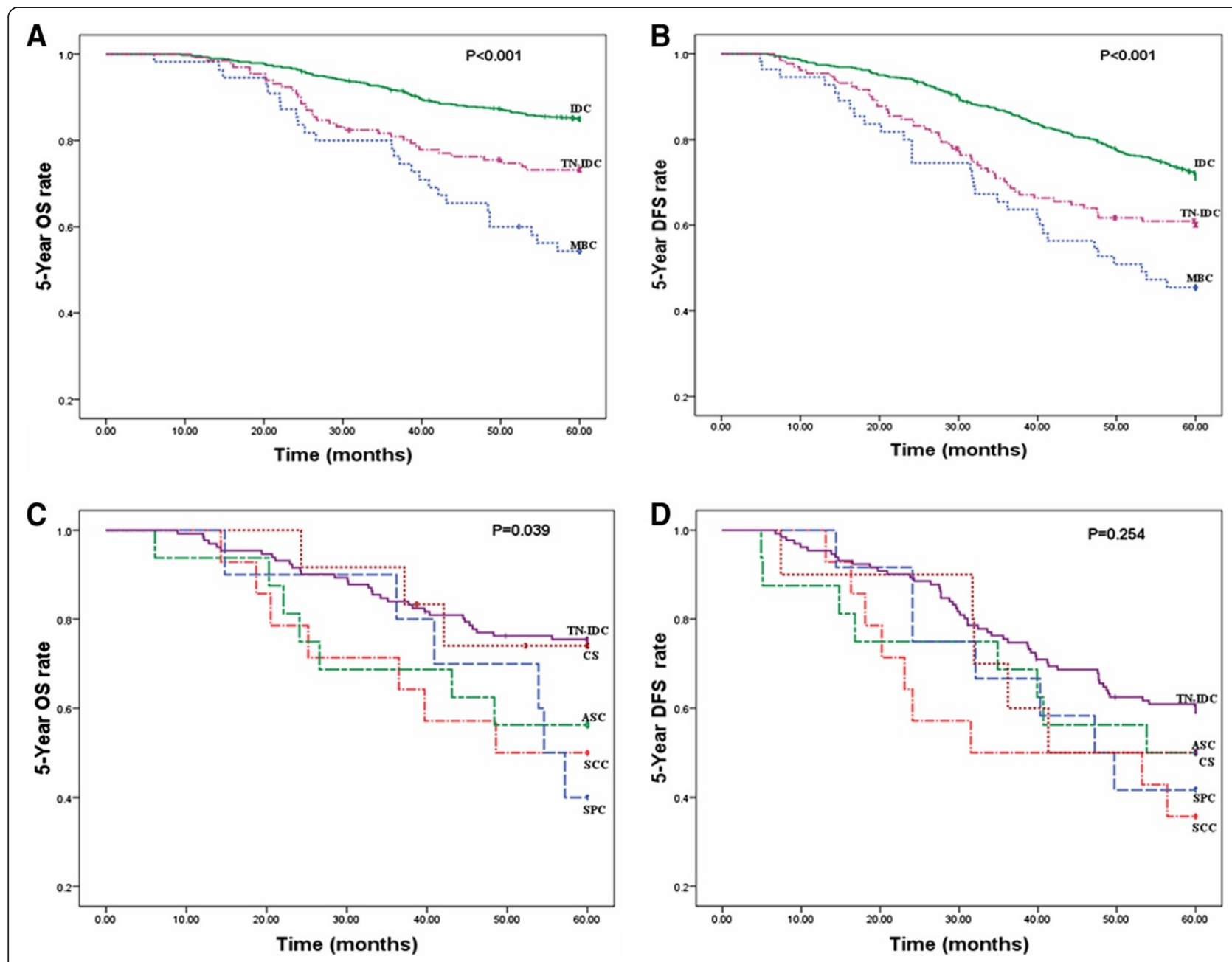

Figure 2 Survival curves. (A) Five-year OS curves based on MBC, IDC and TN-IDC. (B) Five-year DFS curves based on MBC, IDC and TN-IDC. (C) Five-year OS curves for SCC, ASC, SPC, CS and TN-IDC. (D) Five-year DFS curves for SCC, ASC, SPC, CS and TN-IDC.ASC, adenosquamous carcinoma; CS, carcinosarcoma; DFS, disease-free survival; IDC, Invasive ductal carcinoma; MBC, metaplastic breast carcinoma; OS, overall survival; SCC, squamous cell carcinoma; SPC, adenocarcinoma with spindle cell differentiation; TN-IDC, triple-negative invasive ductal carcinoma; TN-MBC, triple-negative metaplastic breast carcinoma.

Table 3 Multivariate analysis of 5-year overall survival and 5-year disease-free survival in metaplastic breast cancer

\begin{tabular}{|c|c|c|c|c|c|c|}
\hline & \multicolumn{3}{|c|}{ 5-year OS } & \multicolumn{3}{|c|}{ 5-year DFS } \\
\hline & HR & $95 \% \mathrm{Cl}$ & $P$ & HR & $95 \% \mathrm{Cl}$ & $P$ \\
\hline Pathological tumor stage $(>T 3)$ & 3.224 & 1.32 to 7.89 & 0.010 & 2.962 & 1.19 to 7.39 & 0.020 \\
\hline Pathological nodal stage (positive) & 3.170 & 1.31 to 7.67 & 0.010 & 1.594 & 1.08 to 2.35 & 0.018 \\
\hline Histological grade (3) & 0.945 & 0.24 to 3.70 & 0.935 & 1.066 & 0.28 to 4.07 & 0.925 \\
\hline P53 ( $\geq 25 \%)$ & 3.274 & 0.40 to 26.72 & 0.268 & 3.413 & 0.43 to 27.38 & 0.248 \\
\hline $\mathrm{Ki}-67(\geq 14 \%)$ & 2.926 & 1.08 to 7.96 & 0.035 & 2.719 & 1.00 to 7.41 & 0.049 \\
\hline Hormone therapy (yes) & 0.290 & 0.06 to 1.42 & 0.126 & 0.341 & 0.07 to 1.68 & 0.185 \\
\hline Subtypes of MBC (SPC) & 1.388 & 0.54 to 3.59 & 0.499 & - & - & - \\
\hline
\end{tabular}

MBC, metaplastic breast cancer;SPC, adenocarcinoma with spindle cell differentiation. 
Table 4 Adjuvant chemotherapy regimens and relapses in $\mathbf{4 8}$ patients with metaplastic breast cancer

\begin{tabular}{|c|c|c|}
\hline Chemotherapy regimen & Number & Patient outcome \\
\hline Cyclophosphamide, methotrexate and fluorouracil & 7 & Seven relapsed. \\
\hline (Fluorouracil), doxorubicin/anthracyclines and cyclophosphamide & 7 & $\begin{array}{l}\text { Two relapse-free at } 45 \text { and } 57 \text { months. One alive and well at } \\
62 \text { months after a local recurrence. Two progressed while } \\
\text { receiving adjuvant therapy. Two relapsed. }\end{array}$ \\
\hline $\begin{array}{l}\text { (Fluorouracil), doxorubicin/anthracyclines and cyclophosphamide to } \\
\text { taxane, paclitaxel/cisplatin/carboplatin }\end{array}$ & 9 & $\begin{array}{l}\text { Five relapse-free at 30, 53, 66, } 69 \text { and } 101 \text { months respectively. } \\
\text { Four relapsed. }\end{array}$ \\
\hline Taxane/paclitaxel, anthracyclines and cyclophosphamide & 18 & $\begin{array}{l}\text { Eight relapse-free at 55, 64, 75, 91, 108, 110, } 123 \text { and } \\
156 \text { months respectively. Ten relapsed. }\end{array}$ \\
\hline $\begin{array}{l}\text { Taxane, anthracyclines and cyclophosphamidein combination } \\
\text { with cisplatin/capecitabine }\end{array}$ & 4 & $\begin{array}{l}\text { Three alive and well at 17, } 25 \text { and } 39 \text { months after a local recurrence. } \\
\text { One alive at } 45 \text { months before a local recurrence, alive at } 20 \text { months } \\
\text { after distant metastasis. }\end{array}$ \\
\hline $\begin{array}{l}\text { Paclitaxel, anthracyclines and cyclophosphamidein combination } \\
\text { with capecitabine/vinorelbine }\end{array}$ & 3 & $\begin{array}{l}\text { Three alive at } 24,29 \text { and } 41 \text { months before a local recurrence, alive at } \\
15,18 \text { and } 25 \text { months after distant metastasis. }\end{array}$ \\
\hline
\end{tabular}

\section{Hormonal therapy}

Of the 55 patients with $\mathrm{MBC}$, 13were treated with tamoxifen as adjuvant treatment. Of these 13 patients, $8(61.5 \%)$ are currently alive and relapse-free. Tamoxifen was used for two patients with metastases, one of whom had an ER-positive tumor, but neither of these patients responded to the treatment.

\section{Discussion}

$\mathrm{MBC}$ is a rare disease that accounts for less than $1 \%$ of all mammary tumors [1]. In our study, the incidence rate of $\mathrm{MBC}$ was only $0.73 \%$. Interestingly, we found that an increasing number of patients with $\mathrm{MBC}$ were reported each year. The World Health Organization only recognized $\mathrm{MBC}$ as a distinct pathological entity in 2000. The increased incidence we noted may represent an actual increase in the disease. Alternatively, it may be a result of improved awareness and recognition by pathologists [4,5], who, since the early immunohistochemical reports more than 10 years ago [16], have increasingly recognized and reported this distinct histologic type of breast cancer. However, because of its rarity, only relatively small series have been reported.

The prognosis of MBC had not been well delineated. Although some investigators have reported a better prognosis for $\mathrm{MBC}$ than IDC, others had reported that the prognosis for MBC was unfavorable compared to IDC $[4,17,18]$. We observed a dismal prognosis for patients with $\mathrm{MBC}$ when compared with 767 patients with IDC, including 131 patients with TN-IDC. Most previous studies have found that the tumor was large at the time of $\mathrm{MBC}$ diagnosis. The median tumor size in our study was $5.0 \mathrm{~cm}$ (range, 1.5 to $20.0 \mathrm{~cm}$ ), larger than the size of an IDC (median $2.3 \mathrm{~cm}$ ) or TN-IDC (median $2.1 \mathrm{~cm}$ ). Pezziet al. [4] reported that the larger sizes of $\mathrm{MBC}$ at clinical presentation appeared to result from a more rapid growth rate.

MBC presented with axillary nodal involvement less frequently than did IDC of the breast. Only 15 of the 55 patients with MBC (27\%) had nodal involvement in our study. These data were consistent with previous reports that showed incidences of axillary nodal involvement at diagnosis of MBC between 6\% and 28\% [19-21]. MBC was usually associated with a lower incidence of axillary nodal involvement than that of an IDC with similar size. Patients with $\mathrm{MBC}$ had a median tumor size of $5.0 \mathrm{~cm}$. Data from patients with an adenocarcinoma of the breast without metaplasia suggested that, for tumors ranging in size from 2.0 to $4.0 \mathrm{~cm}$, the expected frequency of axillary node involvement was greater than $50 \%$ [12]. In our study, only nine of 40 patients with MBC (22\%) with tumor sizes between 3.0 and $5.0 \mathrm{~cm}$ were axillary node-positive. SLN biopsy was adaptive in patients with MBC before axillary lymph node dissection. Despite $\mathrm{MBC}$ being less likely to present with positive axillary lymph nodes, the risk of developing metastatic disease was greater than in typical adenocarcinoma of the breast. It was believed that hematogenous spread was more common in $\mathrm{MBC}$. The above data support the concept that MBC is an aggressive tumor with a high risk of recurrence following the primary site therapy.

In our study, there was a very low incidence of hormone receptor positivity in $\mathrm{MBC}$ compared to IDC. Hormonal therapy was rarely provided to patients with $\mathrm{MBC}$, consistent with the low incidence of hormone receptor positivity in these patients. Rosen [22] noted that the lack of ER and PR might be due to the absence of a prominent glandular epithelial compartment in these tumors. Previous studies have found HER2 over-expression ranging from 4\% to $17 \%$ $[9,23]$. In our study, nine of 35 patients with MBC (26\%) had HER2 over-expression, consistent with previous studies. Triple-negative cases accounted for $67 \%$ of MBC, within the range of previous studies, where $64 \%$ to $96 \%$ of patients with MBC showed triple-negativity [5,9].

Notably, mastectomy was performed more often for patients with $\mathrm{MBC}$. This was likely due to a larger tumor: 
tumor size was $>5 \mathrm{~cm}$ in $40 \%$ of patients with $\mathrm{MBC}$ compared with only $5 \%$ of patients with IDC. As a consequence of the lower rate of breast conservation and less nodal involvement, postoperative radiation therapy was performed less often for patients with $\mathrm{MBC}$; however, these patients underwent chemotherapy more often due to their negative hormone receptor status and larger tumor size. In our study, patients who underwent mastectomy had an unfavorable survival rate during the follow-up period.

Recently, significant progress had been made in the field of MBC biology, which could hypothetically explain its far more aggressive nature compared with other triple-negative breast cancers. Lien et al. [24] elucidated and validated that the epithelial-mesenchymal transition-related genes were differentially up-regulated in MBC compared with IDC, and Hennessy et al. [25] demonstrated that MBC was distinct from basal-like cancers. MBC showed a close relationship with basal-like cancers and a novel subgroup of receptor-negative breast cancers. The patients with the features of both $\mathrm{MBC}$ and basal-like cancers had enrichment for stem cell-like markers with an elevation of CD29/CD24 and CD44/CD24 ratios.

Further research on the mechanisms of carcinogenesis and the potential importance of new molecular markers (for example, P63, Zinc Finger E-box Binding Homeobox 1 (ZEB1), B-cell lymphoma $2(\mathrm{Bcl}-2))$ are needed to develop better prognostic factors for this disease. If our data were confirmed, patients with $\mathrm{MBC}$, particularly those with metastatic disease, would be appropriate candidates for clinical trials evaluating new combinations of the active chemotherapy agents for breast cancer. Considering the differences in the clinical and biologic behavior of these tumors compared with IDC and TN-IDC, clinical trials designed specifically for MBC would be very helpful to further characterize the biology and therapy of this disease. In this study, the number of $\mathrm{MBC}$ cases is too small to convincingly determine the prognostic factors that affect treatment outcomes of MBC compared with IDC, therefore more cases and longer follow-up may be necessary for this type of analysis.

\section{Conclusions}

MBC had distinct clinicopathological features, which include a larger tumor size at presentation, higher Ki-67proliferation index, and a higher proportion of ER-negative and/or PR-negative tumors compared to IDC and TN-IDC. Our study demonstrated that MBC was an extremely aggressive disease and showed poorer prognosis compared with general IDC and TN-IDC. We found that better systemic treatment was required to prevent recurrence. Poor prognostic indicators for MBC include a tumor size larger than $5.0 \mathrm{~cm}$, lymph node involvement and Ki-67 $\geq 14 \%$.

\section{Abbreviations}

ASC: Adenosquamous carcinoma; COC: Carcinoma with osseous and chondroid metaplasia; CS: Carcinosarcoma; DFS: Disease-free survival; ER: Estrogen receptor; HER2: Human epidermal growth factor receptor-2; HR: Hazard ratio; IDC: Invasive ductal carcinoma; IHC: Immunohistochemistry; MBC: Metaplastic breast carcinoma; OS: Overall survival; PR: Progesterone receptor; SCC: Squamous cell carcinoma; SLN: Sentinel lymph node; SPC: Adenocarcinoma with spindle cell differentiation; TN-IDC: Triplenegative invasive ductal carcinoma; TN-MBC: Triple-negative metaplastic breast carcinoma.

\section{Competing interests}

The authors declare that they have no competing interests.

\section{Authors' contributions}

YS, XL, HS and DP conceived the study, carried out the analyses and wrote the manuscript. GZ and YR provided patients and samples, obtained followup data and helped to draft the manuscript. XH, YW, SS and JZ added experimental data, participated in the interpretation of the data and in writing the manuscript. $\mathrm{XL}, \mathrm{QS}$ and $\mathrm{YZ}$ performed the statistical analysis. All authors read and approved the final manuscript.

\section{Acknowledgments}

We thank Xian-Yu Zhang for technical assistance. We thank Jing-ShuGeng and Xiao-Mei Li for assistance with immunohistochemistry staining analysis.

\section{Author details}

1'Department of Breast Surgery, The Third Affiliated Hospital of Harbin Medical University, 150 Haping Road, Harbin 150081, China. ${ }^{2}$ Department of Pathology, The Third Affiliated Hospital of Harbin Medical University, 150 Haping Road, Harbin 150081, China. ${ }^{3}$ Lovelace Health System Pathology, Lovelace Medical Center, 601 Dr Martin Luther King, Albuquerque, NM 87106, USA. ${ }^{4}$ Department of Tumor Surgery, Heilongjiang Province Land Reclamation Headquarters General Hospital, 235 Hashuang Road, Harbin 150088, China. ${ }^{5}$ Heilongjiang Institute for Cancer Research, 6 Baojian Road, Harbin 150040, China.

Received: 13 November 2012 Accepted: 12 May 2013

Published: 6 June 2013

\section{References}

1. Tavassoli FA: Classification of metaplastic carcinomas of the breast. Pathol Annu 1992, 27:89-119.

2. Bocker W: WHO classification of breast tumors and tumors of the female genital organs: patholog and genetics. Verh Dtsch Ges Pathol 2002, 86:116-119.

3. Chao TC, Wang CS, Chen SC, Chen MF: Metaplastic carcinomas of the breast. J Surg Oncol 1999, 71:220-225.

4. Pezzi CM, Patel-Parekh L, Cole K, Franko J, Klimberg VS, Bland K: Characteristics and treatment of metaplastic breast cancer: analysis of 892 cases from the National Cancer Data Base. Ann Surg Oncol 2007, 14:166-173.

5. Jung SY, Kim HY, Nam BH, Min SY, Lee SJ, Park C, Kwon Y, Kim EA, Ko KL, Shin KH: Worse prognosis of metaplastic breast cancer patients than other patients with triple-negative breast cancer. Breast Cancer Res Treat 2010, 120:627-637.

6. Rakha EA, Ellis IO: Triple-negative/basal-like breast cancer: review. Pathology 2009, 41:40-47.

7. Beatty JD, Atwood M, Tickman R, Reiner M: Metaplastic breast cancer: clinical significance. Am J Surg 2006, 191:657-664.

8. Korsching E, Jeffrey SS, Meinerz W, Decker T, Boecker W, Buerger H: Basal carcinoma of the breast revisited: an old entity with new interpretations. J Clin Pathol 2008, 61:553-560.

9. Barnes PJ, Boutilier R, Chiasson D, Rayson D: Metaplastic breast carcinoma: clinical-pathologic characteristics and HER2/neu expression. Breast Cancer Res Treat 2005, 91:173-178.

10. Hennessy BT, Krishnamurthy S, Giordano S, Buchholz TA, Kau SW, Duan Z, Valero V, Hortobagyi GN: Squamous cell carcinoma of the breast. J Clin Oncol 2005, 23:7827-7835.

11. Gibson GR, Qian D, Ku JK, Lai LL: Metaplastic breast cancer: clinical features and outcomes. Am Surg 2005, 71:725-730. 
12. Park HS, Park S, Kim JH, Lee JH, Choi SY, Park BW, Lee KS: Clinicopathologic features and outcomes of metaplastic breast carcinoma: comparison with invasive ductal carcinoma of the breast. Yonsei Med J 2010, 51:864-869.

13. Hammond ME, Hayes DF, Dowsett M, Allred DC, Hagerty KL, Badve S, Fitzgibbons PL, Francis G, Goldstein NS, Hayes M, Hicks DG, Lester S, Love R, Mangu PB, MCShane L, Miller K, Osborne CK, Paik S, Perlmutter J, Rhodes A, Sasano H, Schwartz JN, Sweep FC, Taube S, Torlakovic EE, Valenstein P, Viale G, Visscher D, Wheeler T, Williams RB, et al: American Society of Clinical Oncology/College of American Pathologists guideline recommendations for immunohistochemical testing of estrogen and progesterone receptors in breast cancer. J Clin Oncol 2010, 28:2784-2795.

14. Wolff AC, Hammond ME, Schwartz JN, Hagerty KL, Allred DC, Cote RJ, Dowsett M, Fitzgibbons PL, Hanna WM, Langer A, McShane LM, Paik S, Pegram MD, Perez EA, Press MF, Rhodes A, Sturgeon C, Taube SE, Tubbs R, Vance GH, van de Vijver M, Wheeler TM, Hayes DF: American Society of Clinical Oncology/College of American Pathologists guideline recommendations for human epidermal growth factor receptor 2 testing in breast cancer. J Clin Oncol 2007, 25:118-145.

15. Cheang MC, Chia SK, Voduc D, Gao D, Leung S, Snider J, Watson M, Davies S, Bernard PS, Parker JS, Perou CM, Ellis MJ, Nielsen TO: Ki67 index, HER2 status, and prognosis of patients with luminal B breast cancer. J Natl Cancer Inst 2009, 101:736-750.

16. Bellino R, Arisio R, D'Addato F, Attini R, Durando A, Danese S, Bertone E, Grio R, Massobrio M: Metaplastic breast carcinoma: pathology and clinical outcome. Anticancer Res 2003, 23:669-673.

17. Bae SY, Lee SK, Koo MY, Hur SM, Choi MY, Cho DH, Kim S, Choe JH, Lee JE, Kim TH, Kim JS: The prognoses of metaplastic breast cancer patients compared to those of triple-negative breast cancer patients. Breast Cancer Res Treat 2011, 126:471-478.

18. Luini A, Aguilar M, Gatti G, Fasani R, Botteri E, Brito JA, Maisonneuve P, Vento AR, Viale G: Metaplastic carcinoma of the breast, an unusual disease with worse prognosis: the experience of the European Institute of Oncology and review of the literature. Breast Cancer Res Treat 2007, 101:349-353.

19. Wargotz ES, Norris HJ: Metaplastic carcinomas of the breast. I. Matrixproducing carcinoma. Hum Pathol 1989, 20:628-635.

20. Wargotz ES, Deos PH, Norris HJ: Metaplastic carcinomas of the breast. II. Spindle cell carcinoma. Hum Pathol 1989, 20:732-740.

21. Wargotz ES, Norris HJ: Metaplastic carcinomas of the breast. III. Carcinosarcoma. Cancer 1989, 64:1490-1499.

22. Mourad WA: Book review: Rosen's breast pathology. Ann Saudi Med 1998 $18: 278$.

23. Khan HN, Wyld L, Dunne B, Lee AH, Pinder SE, Evans AJ, Roertson JF: Spindle cell carcinoma of the breast: a case series of a rare histological subtype. Eur J Surg Oncol 2003, 29:600-603.

24. Lien HC, Hsiao YH, Lin YS, Yao YT, Juan HF, Kuo WH, Hung MC, Chang K, Hsieh FJ: Molecular signatures of metaplastic carcinoma of the breast by large-scale transcriptional profiling: identification of genes potentially related to epithelial-mesenchymal transition. Oncogene 2007, 26:7859-7871.

25. Hennessy BT, Gonzalez-Angulo AM, Stemke-Hale K, Gilcrease MZ, Krishnamurthy S, Lee JS, Sahin A, Agarwal R, Joy L, Liu W, Stivers D, Baggerly K: Characterization of a naturally occurring breast cancer subset enriched in epithelial-to-mesenchymal transition and stem cell characteristics. Cancer Res 2009, 69:4116-4124.

doi:10.1186/1477-7819-11-129

Cite this article as: Song et al: Unique clinicopathological features of metaplastic breast carcinoma compared with invasive ductal carcinoma and poor prognostic indicators. World Journal of Surgical Oncology 2013 11:129.

\section{Submit your next manuscript to BioMed Central and take full advantage of:}

- Convenient online submission

- Thorough peer review

- No space constraints or color figure charges

- Immediate publication on acceptance

- Inclusion in PubMed, CAS, Scopus and Google Scholar

- Research which is freely available for redistribution

Submit your manuscript at www.biomedcentral.com/submit
Ciomed Central 